\title{
ANTERIOR ABDOMINAL WALL SEBACEOUS HORN- A RARE CASE
}

\author{
Shanta B. Patil1, Raviprakash ${ }^{2}$
}

${ }^{1}$ Associate Professor, Department of General Surgery, MR Medical College, Kalaburagi, Karnataka, India. ${ }_{2}^{2}$ Postgraduate Student, Department of General Surgery, MR Medical College, Kalaburagi, Karnataka, India.

HOW TO CITE THIS ARTICLE: Patil SB, Raviprakash. Anterior abdominal wall sebaceous horn- a rare case. J. Evolution Med. Dent. Sci. 2018;7(33):3728-3729, DOI: 10.14260/jemds/2018/837

\section{PRESENTATION OF CASE}

A 42-year-old male presented with a raised, painless growth over the anterior abdominal wall of more than six years duration. The clinical examination demonstrated a coneshaped horn-like growth [Figure-1]. After careful and detailed physical examination, the lesion was excised, and abdominal wall defect was repaired with satisfactory result. Specimen was evaluated microscopically. Microscopically, the horn consisted of a mixture of squamous epithelial cells and trichilemmal keratinised debris. The follow-up was uneventful without signs of recurrence. Sebaceous horn or cutaneous horn of anterior abdominal wall is a rare clinical entity. The case of a giant sebaceous horn on the anterior abdominal wall presenting in a 42 -year-male, which was successfully excised, and defect repaired was reported.

Cutaneous horn (Cornu cutaneum) is a relatively uncommon lesion consisting of a projectile, conical, dense, hyperkeratotic nodule, which resembles the horn of an animal.[1] The horn is composed of compacted keratin. Cutaneous horns most frequently occur in sun-exposed parts and are typically found on the face and scalp, but may also occur on the hands, penis, eyelids, nose, chest, neck and shoulder and rarely few cases have been reported where it presents itself on anterior abdominal wall. The cutaneous horns are usually benign; however, malignant or premalignant lesions might be associated with it. [2] Because of their malignant potential, the lesions must always be considered for histopathological evaluation.

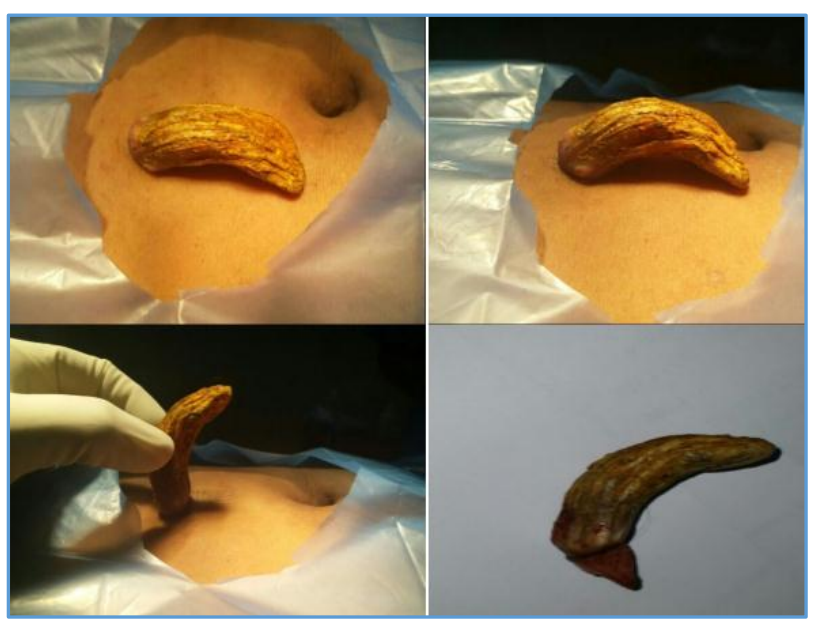

Figure 1

'Financial or Other Competing Interest': None.

Submission 27-01-2018, Peer Review 27-07-2018,

Acceptance 03-08-2018, Published 13-08-2018.

Corresponding Author:

Dr. Raviprakash

Boy's Hostel, Basaweshwar Hospital Campus,

Sadam Road, Kalaburagi- 585105, Karnataka, India.

E-mail: drravih2b@gmail.com

DOI: $10.14260 / j e m d s / 2018 / 837$

(c) (i) () $\ominus$

\section{DIFFERENTIAL DIAGNOSES}

- Common wart.

- Seborrheic keratosis.

- Actinic keratosis.

- SCC.

- Keratoacanthoma.

- Bowen's disease.

- Melanoma (reported rarely).

- Trichilemmal carcinoma.

- Sebaceous adenoma.

\section{DISCUSSION}

A cutaneous horn (Cornu cutaneum) is a protrusion from the skin consisting of cornified material resembling an animal horn in miniature. However, the animal horns are composed of superficial hyperkeratotic epidermis, dermis with centrally positioned bone. No such well-formed bone is observed in the human horns. The earliest well-documented case of cornu cutaneum from London in 1588 is of Mrs. Margaret Gryffith, an elderly Welsh woman. However, earliest observations on cutaneous horns in humans were described by the Everard Home in 1791.[3] Farris from Italy first described the welldocumented case report with adequate histology of gigantic horn in a man. ${ }^{[4]}$ These horns may arise from a variety of benign, premalignant or malignant epidermal lesions. Most commonly, they are single and arise from a seborrheic keratosis lesion.[5] According to a largest study by $\mathrm{Yu}$ et $\mathrm{al}^{,[2]} 61 \%$ of cutaneous horns were derived from benign lesions and $39 \%$ were derived from malignant or premalignant epidermal lesions. Two other larger studies on cutaneous horn also showed that $23 \%-37 \%$ of horns were associated with actinic keratosis or Bowen's disease and another 16\% - 20\% with malignant lesions.[2],[6]

\section{History}

Cutaneous horns usually are asymptomatic. Because of their excessive height, they can be traumatised. This may result in inflammation at the base with resulting pain. Rapid growth is common in presentation.

\section{Physical Examination}

Cutaneous horns can occur anywhere on the body. However, the more typical distribution is on sun-exposed areas, particularly the face, pinna, nose, forearms and dorsal hands. Thirty percent of cases have been seen to arise on the scalp and upper face. They are most commonly a solitary lesion.

It is a hyperkeratotic papule with the height greater than one-half the width of the base. Usually, a cutaneous horn is several millimeters long, but they can grow to be quite large, upto $25 \mathrm{~cm}$ in some cases and $36 \mathrm{~cm}$ diameter in historic cases. 


\section{PATHOLOGICAL DISCUSSION}

The important consideration in these cases is not the horn, but the underlying pathology which may be benign (Seborrheic keratosis, viral warts, histiocytoma, inverted follicular keratosis, verrucous epidermal nevus, molluscum contagiosum, etc.), premalignant (Solar keratosis, arsenical keratosis, Bowen's disease) or malignant (Squamous cell carcinoma, rarely basal cell carcinoma, metastatic renal carcinoma, granular cell tumour, sebaceous carcinoma or Kaposi's sarcoma.[7] Histopathological examination, specially of the base of the lesion[1],[8],[9] is necessary to rule out associated malignancy and full excision and reconstruction is the treatment of choice. The cutaneous horns are predominantly benign lesions; however, possibility of malignant potential should always be kept in mind.

\section{Histologic Findings}

The horn is composed of compact hyperkeratosis, which may be either orthokeratotic or parakeratotic in nature as shown in the image below.

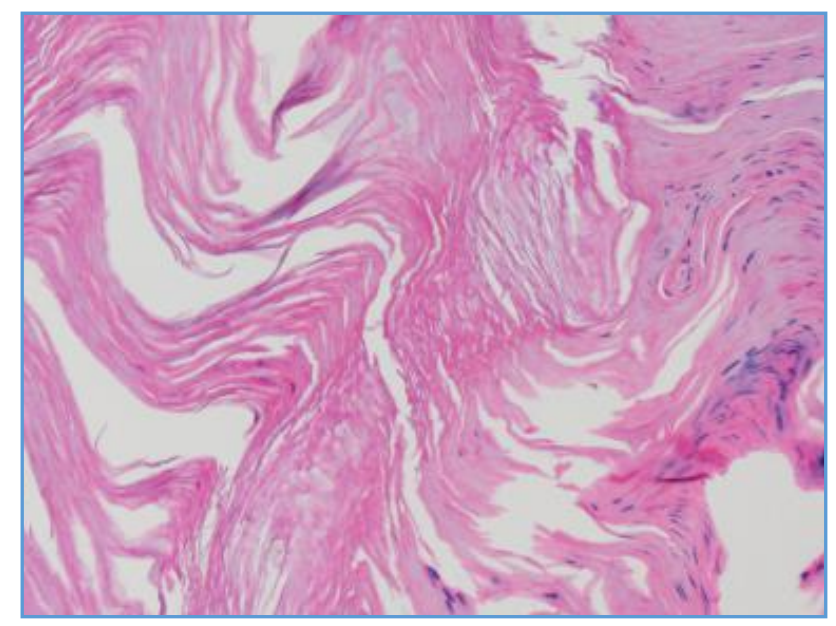

Figure 2. Medium Power View of the Mixed Hyperparakeratosis and Hyperorthokeratotic Keratin that makes up the Actual Horn (Haematoxylin and Eosin [H and E] Stain, Original Magnification 20x)

\section{DISCUSSION ON MANAGEMENT}

Treatment recommendation is contingent upon the type of lesion at the base. In order to rule out a malignancy, it is essential to perform a biopsy of the lesion that includes the base of the horn. In case of benign lesions at the base of the horn, the biopsy is both diagnostic and therapeutic.

Excise malignancies with appropriate margins. Patients discovered to have horns with an underlying squamous cell carcinoma also should be evaluated for metastasis.

Local destruction with cryosurgery is the first-line treatment for verruca vulgaris, actinic keratosis and molluscum contagiosum. Benign lesions do not require any further therapy after the diagnostic biopsy.

\section{FINAL DIAGNOSIS}

Anterior Abdominal Wall Sebaceous Horn.

\section{REFERENCES}

[1] Korkut T, Tan NB, Oztan Y. Giant cutaneous horn: a patient report. Ann Plast Surg 1997;39(6):654-5.

[2] Yu RC, Pryce DW, Macfarlane AW, et al. A histopathological study of 643 cutaneous horns. Br J Dermatol 1991;124(5):449-52.

[3] Bondeson J. Everard Home, John Hunter and Cutaneous horns: a historical review. Am J Dermatopathol 2001;23(4):362-9.

[4] Farris G. Histological considerations on a case of a voluminous cutaneous horn. Minerva Dermatol 1953;28(7):159-65.

[5] Thappa DM, Laxmisha C. Cutaneous horn of eyelid. Indian Pediatr 2004;41(2):195.

[6] Schosser RH, Hodge SJ, Gaba CR, et al. Cutaneous horns: a histopathologic study. South Med J 1979;72(9):1129-31.

[7] Copcu E, Sivrioglu N, Culhaci N. Cutaneous horns: Are these lesions as innocent as they seem to be? World J Surg Oncol 2004;2:18.

[8] Gould JW, Brodell RT. Giant cutaneous horn associated with verruca vulgaris. Cutis 1999;64(2):111-2.

[9] Kastanioudakis I, Skevas A, Assimakopoulos D, et al. Cutaneous horn of the auricle. Otolaryngol Head Neck Surg 1998;118(5):735. 